\title{
Development of low cost PM Ti alloys by thermomechanical processing of powder blends.
}

\author{
Stella Raynova $^{1, a^{*}}$, Brian Gabbitas $^{1, \mathrm{~b}}$, Leandro Bolzoni ${ }^{1, \mathrm{c}}$, Fei Yang ${ }^{1, \mathrm{~d}}$ \\ ${ }^{1}$ Waikato Center of Advanced Materials, Facility of Science and Engineering, The University \\ of Waikato, Hamilton, New Zealand \\ a stiliana@waikato.ac.nz, ${ }^{b}$ briang@waikato.ac.nz, ${ }^{c}$ leandro@waikato.ac.nz, \\ dyang@waikato.ac.nz
}

Keywords: Ti3Al2V alloy, Ti-Fe alloys, low cost, vacuum sintering (VS), induction sintering (IS), thermomechanical processing.

\begin{abstract}
This research focuses on the development of low cost powder metallurgy (PM) Ti alloys suitable for application in PM thermomechanical processing with mechanical properties comparable to those of wrought Ti6Al4V alloy. The alloy systems studied are Ti3Al2V, Ti5Fe and Ti3.2Fe1Cr0.6Ni0.1Mo (Ti5SS). The alloy mixtures were produced by blending Ti HDH powders with Al40V, 316SS master alloy powders or elemental Fe powder. The blended powders were further consolidated using various methods: high vacuum sintering (HVS), induction sintering (IS), powder compact forging (PCF) and powder compact extrusion (PCE). It is found that, PM Ti3Al2V and Ti5Fe alloy processed by PCE or PCF followed by recrystallization annealing (RA) achieved tensile properties comparable with wrought Ti6Al4V alloy. Tensile properties such as yield strength (YS) of 910MPa, UTS of $1010 \mathrm{MPa}$ and $15 \%$ elongation to fracture for Ti3 $\mathrm{Al} 2 \mathrm{~V}$ alloy are reported. Ti5Fe alloy gives YS and UTS of $870 \mathrm{MPa}$ and $968 \mathrm{MPa}$ respectively, combined with $20.3 \%$ elongation to fracture. The tensile results are related to the microstructure developed during the consolidation processes. The oxygen contamination as a result of the high temperature processing is also reported.
\end{abstract}

\section{Introduction}

Wrought Ti6A14V alloy is one of the most commonly used titanium alloys. With the advantages of the powder metallurgy of near net shaping and material waste reduction, having this alloy in powder form is essential. In powder metallurgy thermomechanical consolidation using low cost hydride dehydrate (HDH) powders, the tensile properties of Ti6Al4V alloy are different from those found in wrought Ti6Al4V. The tensile strength can reach values of over $1250 \mathrm{MPa}$, but this is very often at the expense of ductility [1-4]. The higher YS and UTS are because of two factors: firstly, the severe deformation during thermomechanical processing results in extra strong interparticle cohesion; secondly, the comparatively high oxygen content of the starting Ti or Ti6Al4V HDH powders. Commercial grade Ti HDH powders have an oxygen content of $0.22 \mathrm{wt} \%$ to $0.33 \mathrm{wt} \%$. The high temperature powder consolidation leads to oxygen contamination, so that the final PM Ti6Al4V products end up with an oxygen content of over $0.40 \mathrm{wt} \%$, which is significantly higher when compared with maximum $0.25 \mathrm{wt} \%$ oxygen in Ti6Al4V wrought alloy $[5,6]$. Oxygen is also an $\alpha$-phase stabiliser and this reduces the formability of the alloy. For these reasons, a practical approach utilizing powder metallurgy and thermomechanical processing is to alter the composition of HDH Ti6Al4V alloy. One approach is to reduce the amount of $\mathrm{Al}$ and $\mathrm{V}$ in the alloy. Another approach is to use different alloying elements such as elemental Fe or Fe-based master alloys. Replacing the $\mathrm{V}$ in the Ti6Al4V alloy with iron has been done by other researchers to reduce cost [7-11]. In medical applications this has been investigated because $\mathrm{V}$ is cytotoxic [12-14]. Fe is also known for its good diffusivity in $\mathrm{Ti}$ and it has been added to Ti alloys to improve sinter- 
ability $[8,9,15,16]$. Fe is not widely used in wrought and cast Ti alloys because of the difference in density of these two elements. During smelting this can lead to Fe segregation and the formation of brittle Ti-Fe intermetallic compounds. This can be prevented via PM techniques. In PM thermomechanical processing, such as forging and extrusion, good alloy formability is essential. Fe is a strong $\beta$ stabiliser and alloying Ti with Fe can result in stability of the $\beta$-phase down to $650^{\circ} \mathrm{C}$. This is beneficial for improving formability allowing thermomechanical processing to take place at lower temperatures compared to those used for Ti6Al4V alloy.

In this research, a low cost approach for making Ti PM alloys, with properties comparable to wrought Ti6Al4V was considered: 1) use of Ti HDH powders which are half of the cost of Ti GA powders, 2) reducing the alloy content of Ti6Al4V by half, so that there is only $5 \%$ of alloying constituents, 3) using cheaper and readily available Fe and Fe-based master alloys powders; 4) studying the possibility of using short time IS instead of conventional HVS. Three alloy compositions prepared using a BE approach were studied: Ti3 Al2 V, Ti5Fe and Ti3.2Fe1Cr0.6Ni0.1Mo (orTi5SS). A Ti6Al4V powder blend was also studied for comparison. Four powder consolidation methods were used: two sintering methods i.e. HVS and IS and two thermomechanical processing methods i.e. open die powder compact forging (ODF) and powder compact extrusion (PCE). Some of the consolidated samples were further heat treated by recrystallization annealing (RA). The physical and mechanical properties such as sintered density and tensile properties are presented and compared. The tensile properties were related to the $\alpha$ - and $\beta$-phase morphologies and to their distribution. The degree of oxygen pickup during processing is also reported.

\section{Experimental method}

Pure Ti HDH powders with oxygen content of $0.23 \mathrm{wt} . \%$ and particle size below 75 microns were used as a base material. For preparation of Ti6Al4V and Ti3Al2 V powder blends, the pure Ti was mixed with Al60V40 master alloy with oxygen content of 0.65 wt.\% and particle size below 70 microns. For preparation of Ti5Fe and Ti5SS, Ti was mixed with respectively pure carbonyl Fe (oxygen content of $0.23 \mathrm{wt} . \%$ and particle size below 45 microns) and 316LSS powder (oxygen content of $0.20 \mathrm{wt} . \%$ and particle size below 100 microns). After mixing, the powders were compacted into cylindrical billets using warm powder compaction.

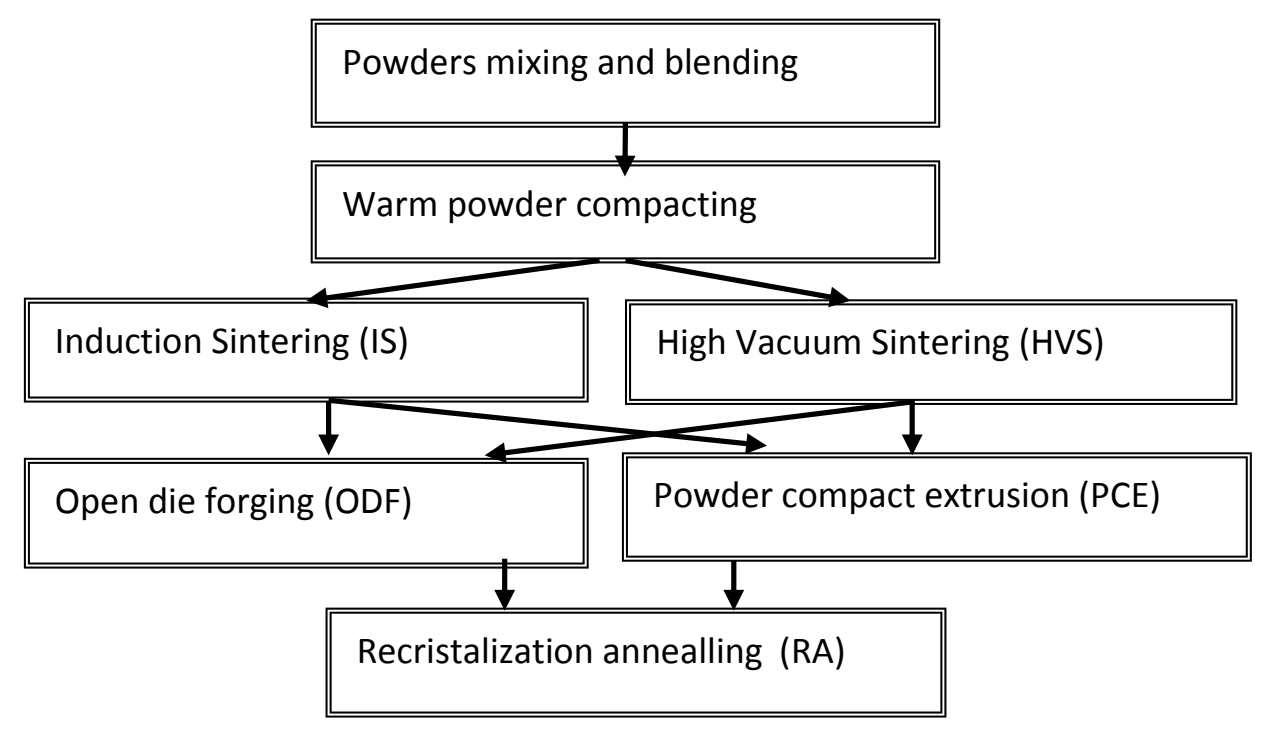

Fig. 1 Processing route for thermomechanical consolidation of Ti6Al4V, Ti3Al2V, Ti5Fe and Ti5SS powder blends. 
The powder compacts were further consolidated by HVS, IS, ODF or PCE. Vacuum sintering was done in two stages: homogenising at $1000^{\circ} \mathrm{C}$ for $2 \mathrm{~h}$ followed by $2 \mathrm{~h}$ sintering at $1300^{\circ} \mathrm{C}$ and $1250^{\circ} \mathrm{C}$ respectively for Ti-Al-V and Ti-Fe based alloys. A temperature of $1000^{\circ} \mathrm{C}$ with a 10 minute sintering time was used for induction sintering. The temperatures used for open die forging and extrusion were $1200^{\circ} \mathrm{C}$ and $1300^{\circ} \mathrm{C}$ respectively for Ti6Al4V and Ti3Al2V samples. The Ti5Fe and Ti5SS samples were respectively forged and extruded at $1100^{\circ} \mathrm{C}$ and $1150^{\circ} \mathrm{C}$. For extrusion a 10:1 extrusion area reduction was used and for forging a height reduction ratio of an average of 3:1 was used. A diagram showing the powder consolidation processing is given in Fig. 1. Two processing routes were used: IS followed by ODF and PCE; and HVS $\left(3.9 \times 10^{-3} \mathrm{~Pa}\right)$ followed ODF and PCE. The IS and associated ODF and PCE were done under argon atmosphere with oxygen kept below 200ppm. The ODF and PCE associated with HVS were carried out in air and before processing, the billets were coated with colloidal graphite. The green densities were calculated from the green powder compact dimensions. Archimedes' principle was used to measure the densities of the sintered samples. Instron 33R4204 machine supplied with an extensometer was used for the tensile testing. Optical microscopy was used for microstructural evaluation.

\section{Results and discussion}

The effect of the sintering method on the sintered densities: The results for relative green densities and the densities after induction or vacuum sintering for all powder compositions are shown in Fig. 2. Compared with the other samples, Ti6Al4V shows a better response to IS with a higher density of $98.5 \%$ and the highest density increase of $6 \%$. Ti3 Al2 V, Ti5SS and Ti5Fe achieved similar IS densities of about $97.3 \%$ with an average density increase of $4 \%$. Vacuum sintering was done in two steps, a soaking time of $2 \mathrm{~h}$ at $1000^{\circ} \mathrm{C}$, allowing diffusion and homogenisation of the alloying elements into the Ti matrix before sintering for $2 \mathrm{~h}$ at a higher temperature. A lower vacuum sintering temperature used for the Ti-Fe based samples was utilised to avoid a possible eutectic reaction and formation of a liquid phase. Ti6Al4V and Ti3Al2V vacuum sintered samples achieved relative densities of $99.5 \%$. The VS densities of Ti5SS and Ti5Fe were lower at $98.7 \%$. This could be because of the lower sintering temperature. The tensile properties of the as sintered samples are shown in Fig. 3 as a comparison with the tensile properties of the further thermomechanically treated samples.

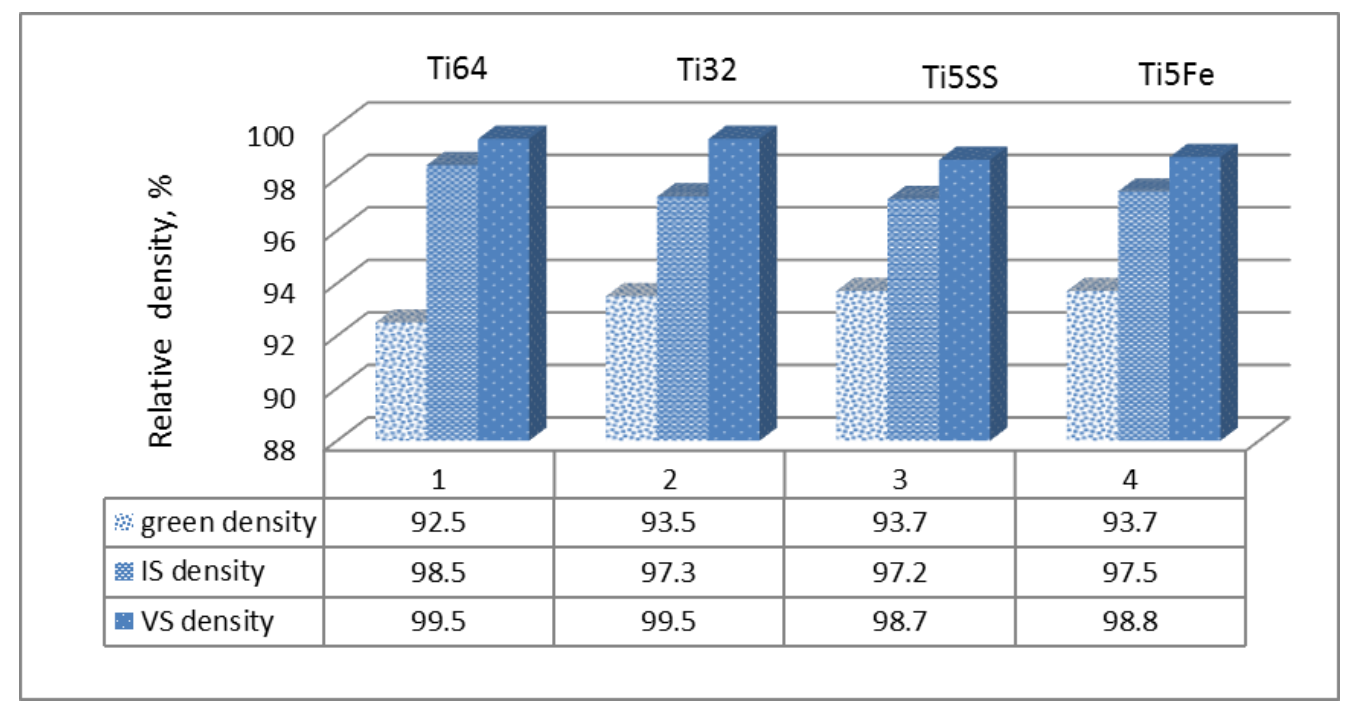

Fig. 2 Effect of the sintering method on the relative density on the consolidated samples. 
Effect of the consolidation method on tensile properties: The tensile results are for test pieces taken from a direction perpendicular to the forging direction in forged discs and parallel to the extrusion direction in extruded bars. For sintered samples, the tensile test pieces were cut in a direction parallel to the flat surface of the sintered cylindrical samples.
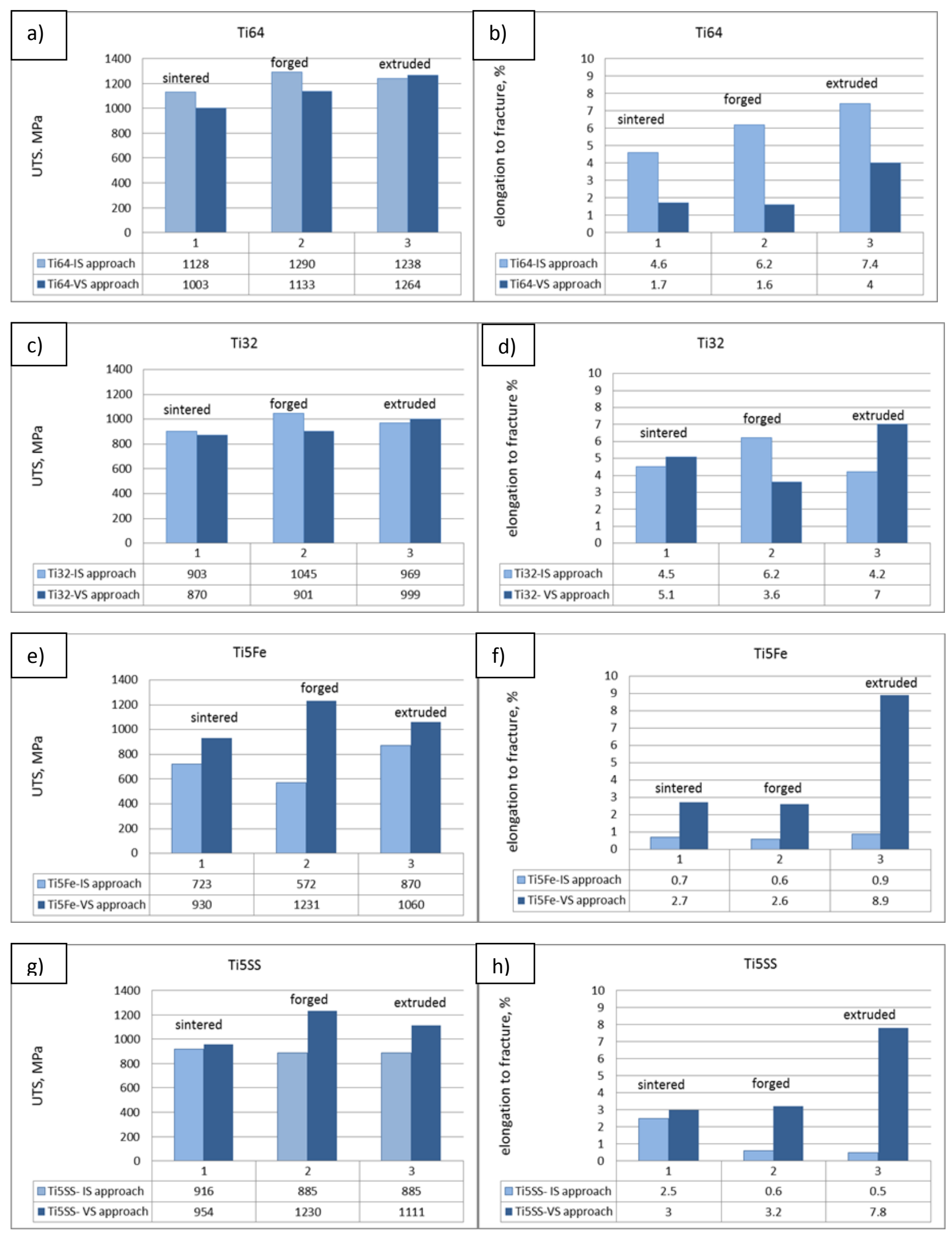

Fig. 3 Tensile properties of a) and b) Ti6Al4V, c) and d) Ti3Al2V, e) and f) Ti5Fe g) and h)Ti5SS consolidated by IS, VS, ODF and PCF. 
Consolidation by induction sintering gave comparatively better results for Ti6Al4V and Ti3Al2V alloys. A short time induction sintering of 10 min resulted in UTS of $1128 \mathrm{MPa}$ for Ti6Al4V and 903MPa for Ti3Al2 V respectively, with similar ductility of $4.5 \%$. The relatively high values of UTS and presence of ductility indicate that powder consolidation was achieved after a short induction sintering time. Even though the induction sintered densities are lower than the density achieved after HVS, the properties are comparable, if not slightly higher of those obtained after HVS. After thermomechanical treatment by forging and extrusion there was a further increase in tensile strength. Following the IS route, the UTS of the forged and extruded Ti6Al4V were respectively $1290 \mathrm{MPa}$ and $1238 \mathrm{MPa}$. The Ti3Al2 V samples had UTS of $1045 \mathrm{MPa}$ and $969 \mathrm{MPa}$ respectively for the forged and extruded samples. The improvement in UTS is partially an outcome of the enhanced consolidation as a result of hot working. The powder particle deformation during hot working causes a breakdown of the oxide layer on powder particle surfaces so that fresh metal surfaces are exposed. This causes the powder particles to form new, stronger bonds. This effect is well observed in the Ti3Al2V and Ti6Al4V forged and extruded microstructures, where the original sintered $\alpha$-phase boundaries disappeared (Fig. 4) in both IS and VS material. The UTS of samples after VS and forging is considerably lower than that after IS. This is because of the much coarser sintered microstructure after vacuum sintering for $4 \mathrm{~h}$. After forging the coarser grains resulted in a more acicular microstructure which probably contained some $\alpha^{\prime}$ martensite (Figure 4b) and this is the main reason for the lower ductility (Fig. 3b and 3d). After extrusion the elongation to fracture is comparatively higher and not affected excessively from the pre-sintering method. Overall the UTS of the ODF and PCE Ti6Al4V and Ti3Al2V alloys investigated in this study are higher than that found in the corresponding wrought alloys $[5,6,17]$. This is a result of thermomechanical processing plus the effect of higher oxygen content (Table 1). However the higher strength leads to comparatively lower ductility.

For the Ti-Fe based powder blends, the sintering method has a completely opposite effect compare to that found for Ti-Al-V powder blends. Even though the Ti5Fe samples achieved IS density similar to that for Ti3Al2V alloy, the tensile properties of this material were comparatively low UTS of $723 \mathrm{MPa}$ and brittle fracture. Induction sintering for 10min was not enough for sufficient diffusion bonding between the Ti particles. Subsequent forging did not bring about enough powder particle cohesion, but created an opposite effect resulting in the break-up of some of the weaker diffusion bonds. This led to tensile strength lower than that after IS. Induction sintering of Ti5SS powder blends showed slightly better results with UTS of 916MPa similar to that for Ti3A12V. This material also shows some ductility with $2.5 \%$ elongation to fracture. Further thermomechanical treatment by ODF and PCE did not improve the properties. The Ti-Fe based powder alloys showed much better response to vacuum sintering. An achievement of well consolidated microstructures after HVS is evident from higher UTS in the range of $930 \mathrm{MPa}$ to $954 \mathrm{MPa}$ for both alloys with ductility of $2.5 \%$. Further thermomechanical treatment by forging led to high UTS of $1230 \mathrm{MPa}$ and ductility of $3 \%$. The UTS after extrusion was $1060 \mathrm{MPa}$ for Ti5Fe and $1111 \mathrm{MPa}$ for the Ti5SS with elongations to fracture of $7.8 \%$ and $8.9 \%$ respectively.

Microstructure development during thermomechanical treatment: For brevity, only the microstructures for Ti3Al2 V and Ti5Fe are presented. The microstructures of Ti6Al4V are fairly similar to those of Ti3Al2 V, accept the $\beta$-phase is more evident and the grain structure is slightly finer in the Ti6Al4V samples. The microstructures in Ti5Fe and Ti5SS are in most cases are also similar. The as-sintered microstructures consist of rounded grains. The size of these grains is in the range of 70 microns and below, similar to that of the starting Ti powders. This means that these grains derive from the original powder particles, which have developed diffusion bonding without the powder particle boundaries disappearing. Each of these grains is surrounded by $\alpha$-phase. Neighboring grains are shared by the same $\alpha$-phase boundaries where diffusion between the two particles occurs. This is evident for all sintered samples 
excluding the IS Ti5Fe and Ti5SS. This observation is evidence of incomplete consolidation in the IS Ti5Fe and Ti5SS samples and explains why the tensile properties are lower (Figure $3 \mathrm{e}$ to $3 \mathrm{~h}$ ). Each grain consists of closely packed unidirectional elongated $\alpha$-grains. Each $\alpha-$ grain is defined by a fine $\beta$. The size and morphology of the elongated $\alpha$-phase and the surrounding $\beta$-phase is influenced by the sintering method and the alloy system. The IS microstructures show higher porosity than the HVS microstructures (Fig. 4a, 4d and Fig. 5a, $5 \mathrm{~d})$. This is because of the lower sintering temperature and much shorter IS time.
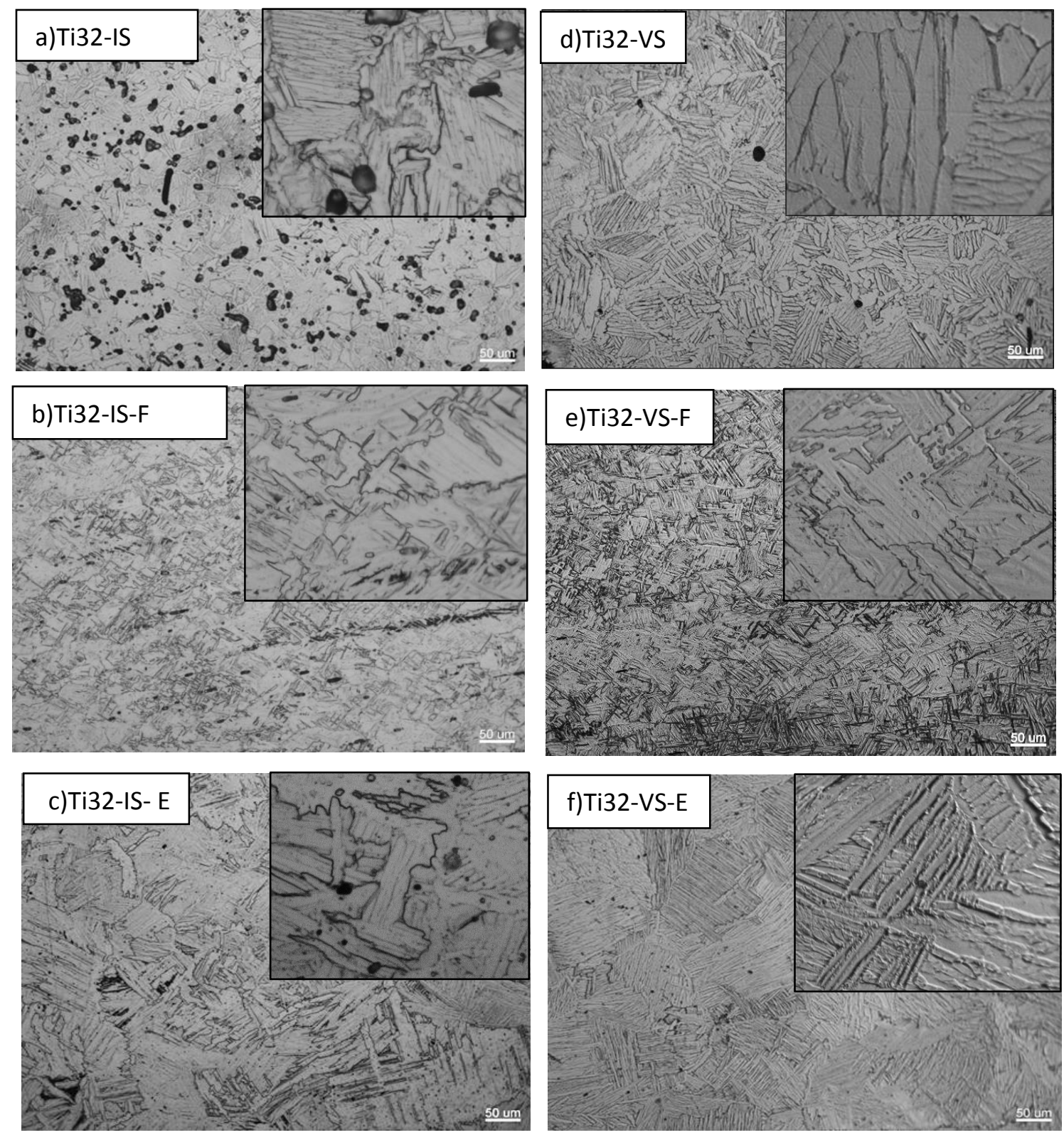

Fig. 4 Optical microscope images of metalographically polished and etched cross section of Ti32 as a result of a) IS, b) IS followed by ODF, c) IS followed by PCE, d) HVS, e) HVS followed by ODF and f) HVS followed by PCE.

An advantage of the short time IS is developing finer sintered microstructures. The finer sintered grain structure resulted in a finer martensitic $\alpha^{\prime}$ phase in the forged structures (Fig. $4 \mathrm{~b}$ ), which in return is beneficial for the tensile strength in the Ti3Al2 V and Ti6Al4V testpieces. On the other hand, the vacuum sintered microstructures were homogeneous with uniform phase distribution (Fig. $4 \mathrm{~d}$ and Fig. 5d), which is a benefit of Ti-Fe alloys. After VS 
of the Ti-Fe based alloys, subsequent forging did not break-up the grains structure, the grains were only flattened, as shown in Figure 5e. The elongated $\alpha$ phase inside each grain disappeared. Instead, a fine martensitic $\alpha^{\prime}$ was formed. This fine martensitic structure is the reason for the high UTS in these samples (Figure $3 \mathrm{e}$ and $3 \mathrm{~g}$ ) and brittle fracture (Figure $3 \mathrm{f}$ and $3 \mathrm{~h}$ ). In the VS and extruded Ti5Fe samples the grain structure was more broken up. A finer secondary equiaxed $\alpha$-phase is distributed throughout the matrix and $\beta$-phase is dispersed along the equiaxed $\alpha$-phase (Fig. 5f). This type of microstructure is the reason for a good combination of tensile strength and ductility in Ti5Fe and Ti5SS extruded rods. The microstructure in Ti5Fe after short time IS shows an uneven distribution of $\beta$-phase ( Fig. 5.a). This suggests that there was incomplete diffusion of elemental iron into the Ti matrix which resulted in $\beta$ rich grains mixed up with Ti rich grains. Further thermomechanical processing did not improve the homogeneity of the microstructure (Fig. 5b and 5c).
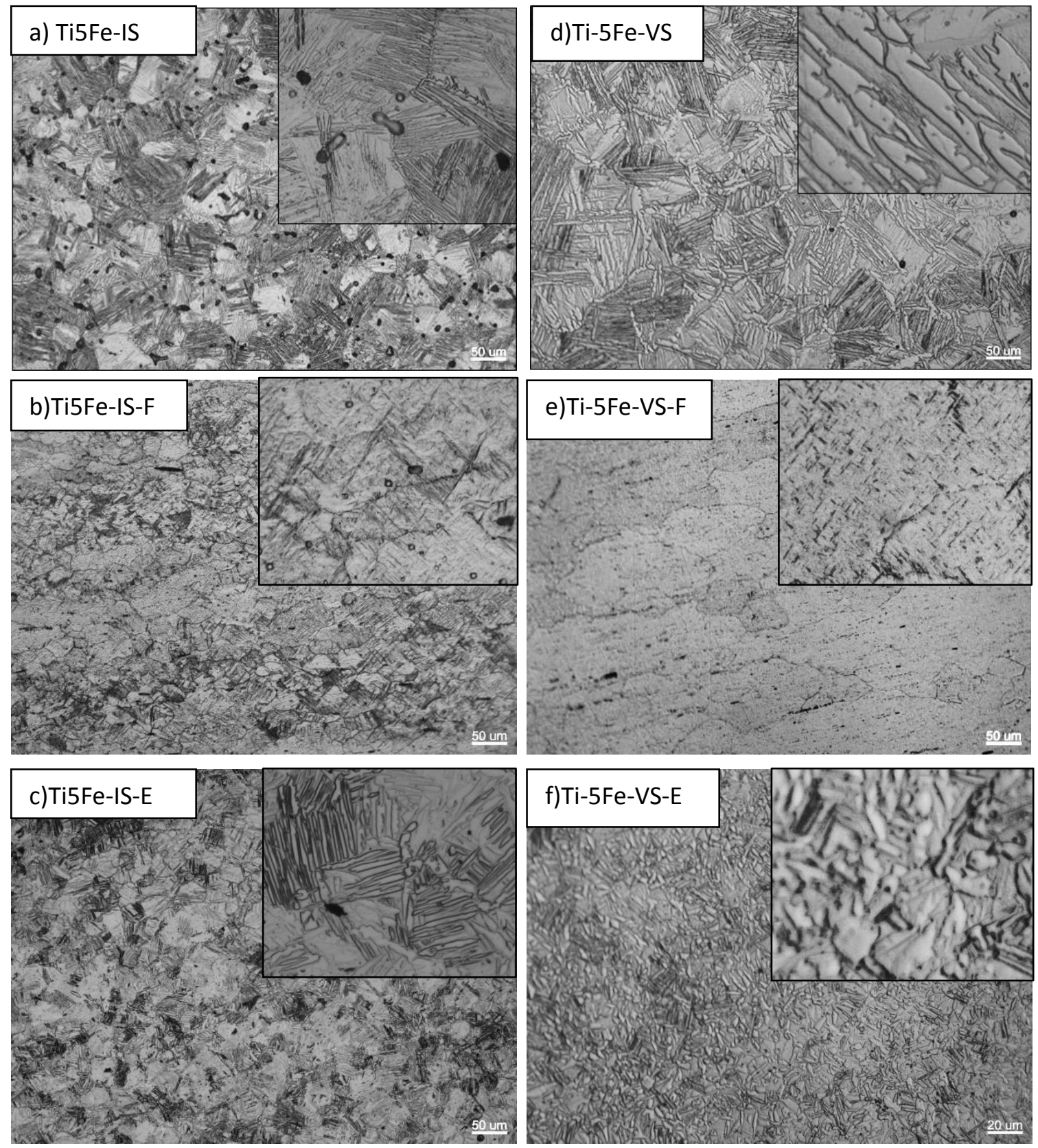

Fig. 5 Optical microscope images of metalographically polished and etched cross section of Ti5Fe as a result of a) IS , b) IS followed by ODF, c) IS followed by PCE, d) HVS, e) HVS followed by ODF and f) HVS followed by PCE. 
Oxygen pick up during sintering and thermomechanical processing: The oxygen content of the as-mixed powder blends was calculated using the oxygen content of the elemental powders and the master alloy powders. The sintering method has little effect on the amount of oxygen pick up. Further reheating after VS, prior to thermomechanical processing did not lead to significant increases in oxygen contamination. The oxygen pick-up for Ti64 was slightly higher than for Ti3Al2V. The Ti5Fe alloy had the lowest oxygen pickup and the lowest oxygen content after thermomechanical processing.

Table 1 Oxygen content of as mixed powder blends and after processing:

\begin{tabular}{|c|c|c|c|c|c|}
\hline Alloy & \multirow{2}{*}{$\begin{array}{l}\text { As mixed } \\
\text { powders } \\
\text { oxygen, wt.\% }\end{array}$} & \multirow{2}{*}{$\begin{array}{l}\text { Sintering } \\
\text { method }\end{array}$} & \multicolumn{3}{|c|}{ Oxygen, wt.\% } \\
\cline { 3 - 6 } & & as sintered & after ODF & after PCE \\
\hline \multirow{2}{*}{ Ti6Al4V } & \multirow{2}{*}{0.272} & IS & 0.44 & - & 0.44 \\
\cline { 3 - 6 } & & VS & 0.45 & 0.47 & 0.45 \\
\hline \multirow{2}{*}{ Ti3A12V } & \multirow{2}{*}{0.251} & IS & 0.44 & 0.40 & 0.40 \\
\cline { 3 - 6 } & & VS & 0.36 & 0.40 & 0.39 \\
\hline \multirow{2}{*}{ Ti5Fe } & 0.235 & IS & 0.34 & 0.33 & 0.38 \\
\cline { 3 - 6 } & & VS & 0.38 & 0.38 & 0.33 \\
\hline \multirow{2}{*}{ Ti5SS } & \multirow{2}{*}{0.229} & IS & 0.32 & 0.34 & 0.39 \\
\cline { 3 - 6 } & & VS & 0.38 & 0.37 & 0.37 \\
\hline
\end{tabular}

Effect of recrystallisation annealing (RA) on the tensile properties: Tensile stress-strain curves for the various alloys after recrystallization annealing and associated microstructures are shown in Figure 6. Recrystallisation annealing has significantly changed the microstructures, causing partial recrystallisation, finer $\alpha$ grains and removal of the martensitic $\alpha^{\prime}$ phase. The RA microstructure in a Ti32-IS-F sample resulted in an average YS of $940 \mathrm{MPa}$, UTS of $970 \mathrm{MPa}$ and elongation to fracture of $12.0 \%$. The yield and tensile strength for alloy Ti32-VS-E were 910MPa and 1010MPa respectively, with an elongation to fracture of $15.3 \%$. For Ti5Fe-VS-E alloy the YS and UTS were $870 \mathrm{MPa}$ and $968 \mathrm{MPa}$ respectively, with $20.3 \%$ elongation to fracture. The tensile properties of these PM alloys produced by thermomechanical treatment are comparable with those for wrought Ti6Al4V alloy with much lower oxygen content.

\section{Conclusions}

- The YS and UTS of PM Ti6Al4Valloy, processed thermomechanically using higher oxygen HDH powders, are considerably higher than the commonly used wrought Ti6Al4V alloy.

- Short-time induction sintering (IS) instead of high vacuum sintering (HVS) can be employed for pre-consolidation of Ti3Al2V and Ti6Al4V powder blends. The IS approach for thermomechanical consolidation of Ti3Al2 $\mathrm{V}$ is beneficial for achieving of good combination of UTS and ductility. 
- Short-time induction sintering did not result in homogenous and fully consolidated structures in the alloys Ti5Fe and Ti5SS and this resulted in very poor tensile properties.

- Powder blends used to make Ti5Fe and Ti5SS alloys were well consolidated after HVS. Further thermomechanical processing using open die forging (ODF) led to UTS of up to $1200 \mathrm{MPa}$. Powder compact extrusion (PCE) resulted in a fine equiaxed microstructure giving high UTS with up to $10 \%$ elongation to fracture.

- In most of the thermomechanically treated samples, a post recristallisation annealing (RA) heat treatment achieved tensile properties comparable to those expected from wrought Ti6Al4V alloy.

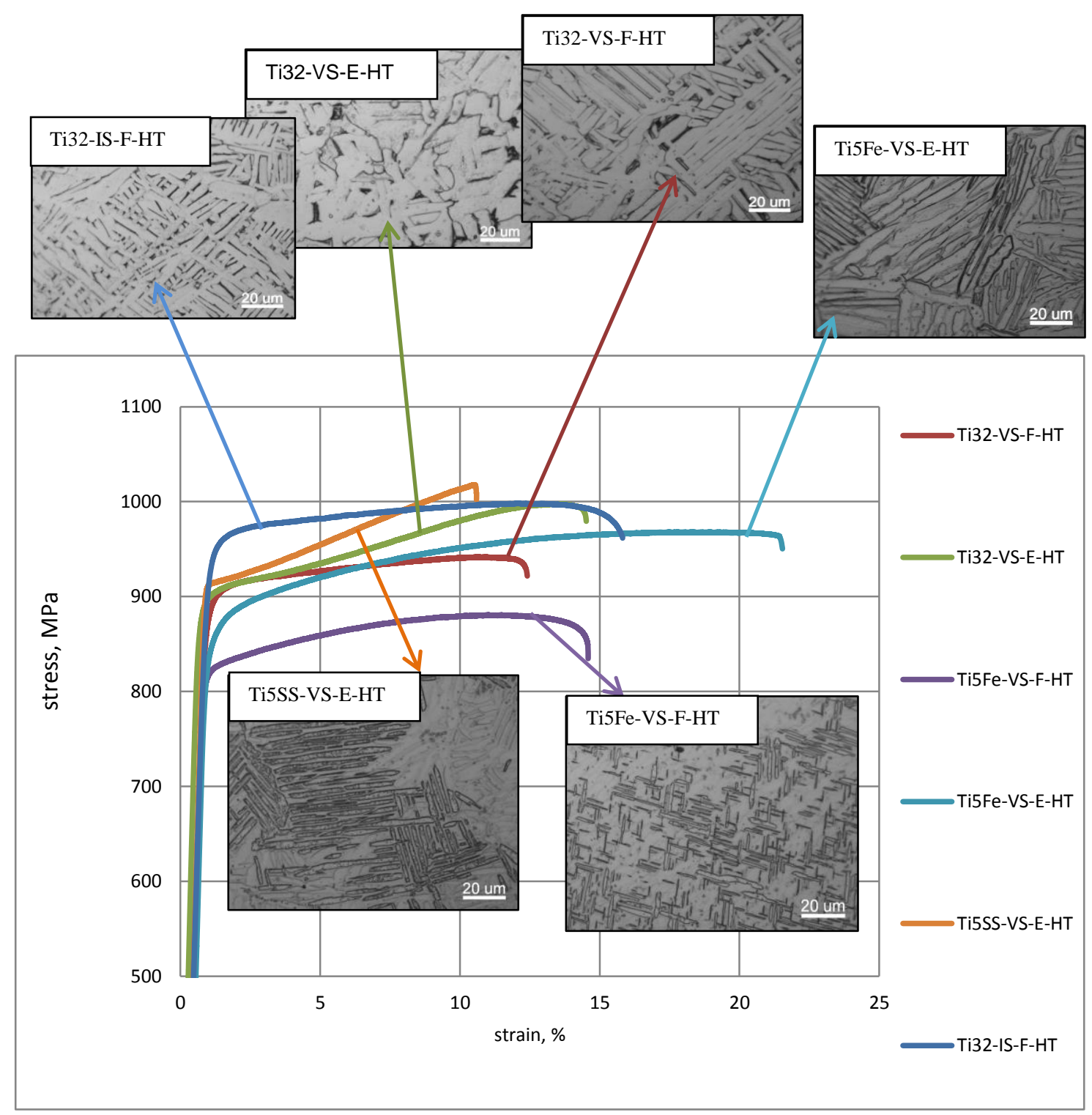

Fig. 6 Representative stress-strain curves for RA heat treated samples and related microstructures.

\section{Acknowledgement}

The funding from the Ministry of Business, Innovation and Employment (MBIE), New Zealand to support this work is gratefully acknowledged. 


\section{References}

[1] B. Gabbitas, F. Yang, S. Raynova, M. Jia, in: Light metals conference, 15-17 October 2014, Trans Tech Publications, South Africa, 2014, pp. 3-11.

[2] M.T. Jia, D.L. Zhang, B. Gabbitas, J.M. Liang, C. Kong, Scripta Materialia, 107 (2015) 10-13.

[3] S. Raynova, Z. Deliang, B. Gabbitas, Key Engineering Materials, 520 (2012) 289-294.

[4] F. Yang, B. Gabbitas, A. Mukhtar, W. Downing, in: Light metals conference 15th-17th Oct 2014, Trans Tech Publications, South Africa, 2014, pp. 241-248.

[5] S. Lampman, Properties and Selection- Nonferrous Alloys and Special Purpose, in: ASM Metals Handbook, pp. 1782-1886.

[6] http://www.aerospacemetals.com/titanium-ti-6al-4v-ams-4911.html, in, ASM Aerospace Specification Metals, Inc.

[7] L. Bolzoni, E. Herraiz, E.M. Ruiz-Navas, E. Gordo, Materials \& Design, 60 (2014) 628-636.

[8] P.G. Esteban, L. Bolzoni, E.M. Ruiz-Navas, E. Gordo, Powder Metallurgy, 54 (2011) 242-252.

[9] P.G. Esteban, E.M. Ruiz-Navas, E. Gordo, Materials Science \& Engineering: A , 527 (2010) 56645669.

[10] R.M. German, J.W. Dunlap, Metallurgical Transactions A, 17A (1986) 205-213.

[11] J. O'Flynn, S.F. Corbin, Journal of Alloys and Compounds, 618 (2015) 437-448.

[12] M. Hagiwara, S.J. Kim, S. Emura, Scripta Materialia, 39 (1998) 1185-1190.

[13] H.-C. Hsu, S.-C. Wu, S.-K. Hsu, Y.-C. Li, W.-F. Ho, Intermetallics, 47 (2014) 11-16.

[14] R.P. Siqueira, H.R.Z. Sandim, A.O.F. Hayama, V.A.R. Henriques, Journal of Alloys and Compounds, 476 (2009) 130-137.

[15] Y. Liu, L.F. Chen, H.P. Tang, C.T. Liu, B. Liu, B.Y. Huang, Materials Science and Engineering A, 418 (2006) 25-35.

[16] H. Nakajima, K. Yusa, Y. Kondo, Scripta Materialia, 34 (1996) 249-253.

[17] http://asm.matweb.com/search/SpecificMaterial.asp?bassnum=MTA321, in, ASM Aerospace Specification Metals, Inc. 